\title{
Tensiometrical and Rheological Parameters of The Blood Serum of Patients Operated on The Heart
}

\author{
Potapov VV ${ }^{1}$, Khomutov EV*1, Kuznetsova IV ${ }^{1}$, Shramenko EK ${ }^{2}$ and Lylyk SV ${ }^{1}$ \\ ${ }^{1}$ Donetsk National Medical University named after M. Gorky, Donetsk, 83003 Ukraine \\ ${ }^{2}$ Medical Institute, Penza State University, Penza, 440026 Russian Federation \\ *Corresponding author: Khomutov EV, Donetsk National Medical University named after M. Gorky, Donetsk, 83003 \\ Ukraine
}

\section{ARTICLE INFO}

Received: March 10, 2020

Published: 慧 March 18, 2020

Citation: Potapov VV, Khomutov EV, Kuznetsova, Shramenko EK, Lylyk S. Tensiometrical and Rheological Parameters of The Blood Serum of Patients Operated on The Heart. Biomed J Sci \& Tech Res 26(4)-2020. BJSTR. MS.ID.004389.

\begin{abstract}
The aim of this study was to establish patterns of changes in surface tension and dilatational viscoelasticity of serum of patients operated on for the heart under cardiopulmonary bypass during intra- and intraoperative periods. The study was conducted in 40 patients with Coronary Heart Disease (CHD) who underwent myocardial revascularization operations. The control group was consisted of 17 individuals without chronic diseases and active complaints aged 50 to 75 years. Experimental studies of surface tension and dilatational viscoelasticity using drop and bubble form methods were performed using PAT-1 and PAT-2 tensiometers (SINTERFACE Technologies, Berlin, Germany). It was found that patients with coronary heart disease compared with healthy volunteers of the same age demonstrate decreasing in both dynamic and equilibrium surface tension by an average of $5-6 \mathrm{mN} / \mathrm{m}$. This behavior of the changes indicates a significant increase in the concentration of surfactants in the blood serum of patients, which can be considered as an adaptive reaction of an organism in response to the development of CHD and CHF. The procedure for transferring patients to cardiopulmonary bypass does not cause changes in the dynamic and equilibrium surface tension of blood serum but leads to an increase in the sensitivity of the dilatation viscosity module to the oscillation frequency. Despite the absence of direct correlation between the biochemical and rheological parameters of the blood serum of patients, the study of surface tension allows reliable identification of patients with severe coronary heart disease and in the long term can become the basis for the development of a quick and cheap method of screening studies.
\end{abstract}

Keywords: Surface Tension; Blood Rheology; Coronary Heart Disease; Valvular Heart Disease

\section{Introduction}

Timely diagnosis of patients with Coronary Heart Disease (CHD) and acquired valvular pathology leads to decreasing of adverse pathological processes numbers, in particular, atherosclerotic lesions of the main arteries, related to the manifestations of multifocal atherosclerosis. A significant part of such patients showed a high level of proatherogenic lipids in serum [1], which are surfaceactive substances (surfactants). Modern metabolic technologies make it possible to directly determine the molecular markers of various diseases, as, for example, this was done in [2]. However, a detailed chemical blood analysis is a complex and expensive process, while measuring of surface tension and dilatational viscoelasticity is the integral characteristic of blood and other fluids [3,4]. This approach led to a significant activity of researchers in relation to interphase (adsorption and rheological) characteristics of serum and plasma upon various pathologies [5-8]. The hemodynamic parameters, composition and properties of blood in micro vessels determine not only the behavior of its flow, but also the forces that 
control the transfer of water and substances through the capillary endothelium [9]. One of the important factors that significantly effectson the capillary hydrostatic pressure and the fluid balance between the microvascular bed and the tissue is blood viscosity and its rheological characteristics.

A significant amount of data has been accumulated as yet, showing the important role of changes in the rheological properties of blood both under normal and pathological processes in the human body [10]. Optimization of blood flow in the extreme conditions serves as an adaptive reaction that increases the reserve capabilities of the circulatory system and the organism as a whole. On the other hand, increasing of blood viscosity and its rheological properties upon pathology leads to a deterioration in its transport capabilities, the appearance of tissue hypoxia, metabolic changes, which to a certain extent determines the prognosis and nature of the course of the underlying disease [11]. The blood contains various high and low molecular weight surfactants, the concentrations of which vary significantly with various pathologies [12], which manifests in a change in their rheological characteristics. However, data on such changes in patients operated on for the heart under Cardiopulmonary Bypass (CPB) are practically absent. Thus, the aim of this study was to establish patterns of changes in surface tension and dilatational viscoelasticity of serum of patients operated on for the heart under cardiopulmonary bypass during intra- and intraoperative periods.

\section{Materials and Methods}

\section{Experimental Part}

Experimental studies of surface tension and dilatational viscoelasticity using drop and bubble form methods were performed using PAT-1 and PAT-2 tensiometers (SINTERFACE Technologies, Berlin, Germany). The technique is described in detail earlier [13]. A drop of blood serum was formed on a vertical capillary with the channel diameter of $1 \mathrm{~mm}$ and the external diameter of $3 \mathrm{~mm}$. The capillary end face has an internal diameter of $2.96 \mathrm{~mm}$. That is, the walls of the end face of the capillary are thin, which eliminates the influence of the contact angle on the shape and size of the droplet. The droplet area was automatically maintained constant during the experiment, within $34-36 \mathrm{~mm}^{2}$ at any surface tension. The volume of the formed droplet is $24-25 \mathrm{~mm} 3$. The drop volume decreases during adsorption due to changing in the drop shape. Experimental studies of dilatational rheology of blood serum were carried out after reaching equilibrium, which required 2000-2500s from the moment of droplet formation.

Dilatational module E characterizes the viscoelastic properties of surface (interphase) layers. Module $\mathrm{E}$ is defined as the ratio of the change in the surface tension of the solution $\gamma$ to the relative change in surface area $A: \quad E=\frac{d}{d \ln A}$
The experiments were performed with harmonic oscillations of the droplet surface area with an amplitude of $\pm 8 \%$ and a frequency of 0.5 to $0.005 \mathrm{~Hz}$. The error in determining surface tension in PAT2 and PAT- 1 is $0.1 \mathrm{mN} / \mathrm{m}$. The error in determining the viscoelastic modulus is several times larger and approximately equal to $0.1 / 0.16=0.6 \mathrm{mN} / \mathrm{m}$. To obtain rheological parameters in the PAT tensiometers, the oscillation frequency, amplitude and number of cycles were set. The calculation of the rheological parameters was carried out by the program included in PAT-2, using the Fourier transform and the model described in [14]. Dilatational module E is presented in [15-17] as a complex indicator that includes real and imaginary components:

$$
E=E_{i}+i E_{i}
$$

where the real part of $\mathrm{E}_{\mathrm{r}}$ is the elastic modulus, $\mathrm{E}_{\mathrm{i}}$ is the imaginary part by which the dilatation viscosity is determined. Expression (2) can be transformed into equations for the viscoelastic modulus $|\mathrm{E}|$ and phase angle $\phi$ :

$$
|E|=\sqrt{E_{r}^{2}+E_{i}^{2}}, \quad \phi=\arctan \left(\frac{E_{i}}{E_{r}}\right)
$$

It can be noted that the results using the drop shape method may differ from rheological parameters for a flat surface. For a flat surface with the diffusion mechanism of adsorption of a surfactant, both components of the module are given by the equations $[15,16]$ :

$$
E_{r}(\omega)=E_{0} \frac{1+\zeta}{1+2 \zeta+2 \zeta^{2}}, \quad E_{i}(\omega)=E_{0} \frac{1+\zeta}{1+2 \zeta+2 \zeta^{2}},
$$

The parameter $\zeta=\sqrt{\omega_{D} / 2 \omega}$ includes the angular frequency $\omega$ and the diffusion relaxation frequency $\omega_{D}(c)=D \cdot(d \Gamma / d c)^{-2}$. The value $E_{0}(c)=-d \gamma / d \ln \Gamma$ is ultimate elasticity, and the parameters $\mathrm{c}, \Gamma$, and D are the volume concentration, adsorption, and diffusion coefficient. Equations (4) can be written in another form:

$$
|E|=E_{0}\left(1+2 \zeta+2 \zeta^{2}\right)^{-1 / 2}, \quad \phi=\operatorname{arctg}[\zeta /(1+\zeta)]
$$

Here $|E|$ is the viscoelastic modulus, and $\phi$ is the phase angle between stress (disturbance) $(d \gamma)$ and deformation (dA). For a spherical drop with radius $\mathrm{R}$ during adsorption from the bulk volume of the drop on its surface, JoosP. obtained the equation:

$$
E(\omega)=\frac{E_{0}}{1+\frac{D}{i \omega R} \frac{d c}{d \Gamma}[n R \operatorname{coth}(n R)-1]}=E_{0}\left\{1-i \frac{D}{\omega R} \frac{d c}{d \Gamma}[n R \operatorname{coth}(n R)-1]\right\}^{-1}
$$

where $n^{2}=i \omega / D$. It is important to note that for the volume of drops and oscillation frequencies used in this work, the results of calculations according to equation (6) are only a few\% less than the results for a flat surface, calculated for the same parameters according to equations (5).

Characterization of Clinical Groups: The study was conducted in 40 patients ( 22 males and 18 females) aged 49 to 70 years (mean age $62.1 \pm 0.9$ ) with Coronary Heart Disease (CHD) who underwent myocardial revascularization operations (aortocoronary or aortomammary coronary artery bypass grafting, from 2 to 4 shunts). Cardiopulmonary Bypass (CB) was performed with use of the 
Terumo System I apparatus, the Terumo Sarns TCM II temperature control device, and Medtronic Affinity NT oxygenators. The volume of the primary filling of the oxygenator with lines was $1300.0 \pm 200$ $\mathrm{ml}$. The following solutions were used: $\mathrm{NaCl} 0.9 \%-700.0 \pm 100.0 \mathrm{ml}$, gelofusine (B.Brown) - $500.0 \mathrm{ml}$, mannitol $15 \%$ based on $0.5 \mathrm{~g} / \mathrm{kg}$ $(200.0 \pm 22 \mathrm{ml})$, sodium bicarbonate $5 \%-100.0 \mathrm{ml}$, heparin 7500 U. The following additives in CB were used: albumin $10 \%-200 \mathrm{ml}$, potassium chloride $7.5 \%-20.0$. Before the start of cardiopulmonary bypass, the perfusate was heated to a temperature of $36.0^{\circ} \mathrm{C}$. Surgical interventions with $\mathrm{CB}$ were performed in conditions of moderate hypothermia $\left(33-34^{\circ} \mathrm{C}\right)$.

To stop cardiac activity and prevent ischemic damage to the myocardium, the method of cold cardioplegia was used (Custodiol, Dr. Franz Köhler Chemie GmbH, Germany). Blood sampling for the study was performed 1 hour before the operation, at the 5th minute of the CB, 12 hours after the operation ( $1{ }^{\text {st }}$ day) and on the 7 th day after the operation. The control group was consisted of 17 individuals without chronic diseases and active complaints aged 50 to 75 years (average age $61 \pm 1.0$ year), 12 of whom were males and 5 - females. The age of the control group donors corresponds to the age of patients in the studied groups. Statistical processing included the calculation of the main parameters of the distribution of random variables. To obtain a representative sample, we used the methodology for determining significant median boundaries. If the law of distribution of the values of the studied indicators differed from the normal law, nonparametric criteria were used.
The analysis was performed using licensed software packages STATISTICA 5.11, Microsoft EXCEL 6.0, and Med Stat [18].

\section{Results and Discussion}

In the Figure 1 the curves of the dynamic surface tension of blood serum for a healthy volunteer and a patient with coronary artery disease were showed. It can be seen that the curve for the patient lies much lower, and equilibrium is achieved in 1500-2000 sec. Therefore, drops area oscillations (rheological studies) were performed at a time of more than $2000 \mathrm{~s}$ (Figure 1). (Table 1) shows the results of studies of blood serum before, during and after surgery. Six parameters are presented: $\gamma 100 \mathrm{~s}$ - dynamic surface tension at an adsorption time of 100 seconds, equilibrium surface tension - $\gamma \infty$ (adsorption time 2500 seconds), viscoelastic modulus, and phase angle $\phi$ at frequencies of 0.1 and $0.01 \mathrm{~Hz}$. The indicated tensiometric and rheological parameters in a number of studies [9-12] were recognized as the most informative. One can see that almost all parameters for patients (except for the phase angle at a frequency of 0.1 ) significantly differ from parameters for healthy people. Both dynamic $\gamma$ at $100 \mathrm{~s}$ and equilibrium $\gamma$ in patients are $5-6 \mathrm{mN} / \mathrm{m}$ less than in healthy ones. This indicates a significant increase in the content of surfactants in the blood of patients. In addition to measuring the tensiometric and rheological parameters for all studied populations, a biochemical analysis of the following blood serum components was performed: glucose, total protein, albumin, urea (Table 2).

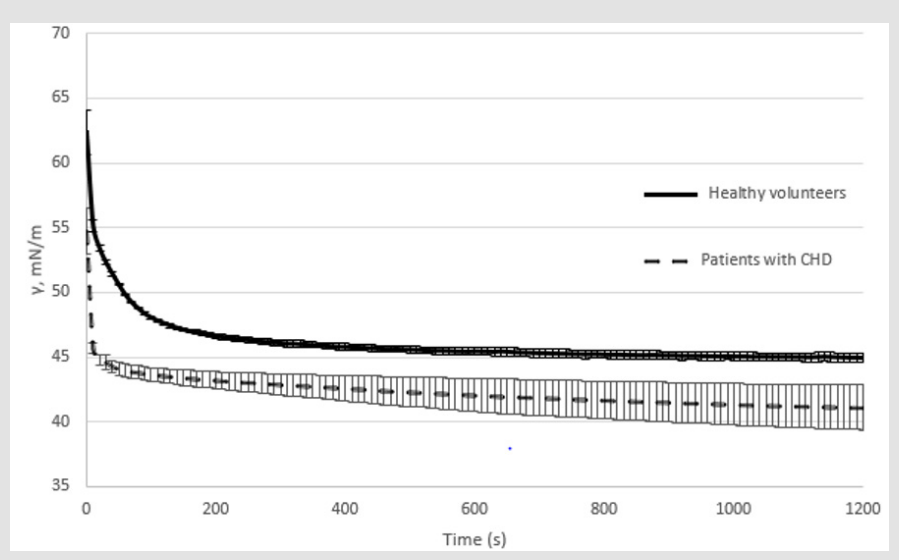

Figure 1: Dynamic surface tension of the blood serum in patients with coronary artery disease and healthy persons. 
Table 1: Comparison of blood serum parameters of patients in relation to the control group and to the preoperative period $(\mathrm{M} \pm \mathrm{Sd}$; Me; (Min-Max).

\begin{tabular}{|c|c|c|c|c|c|c|}
\hline \multirow[b]{2}{*}{ Groups } & \multicolumn{6}{|c|}{ Parameters } \\
\hline & $\begin{array}{c}\gamma, 100 \mathrm{~s}, \\
\text { мН/м }\end{array}$ & $\begin{array}{c}\gamma \infty, \\
\mathbf{M H} / \mathbf{M}\end{array}$ & $\begin{array}{c}\text { E } 0.1 \mathrm{~Hz}, \\
\mathrm{MH} / \mathrm{M}\end{array}$ & $\begin{array}{c}\text { E0.01H, } \\
\text { мH/м }\end{array}$ & $\begin{array}{c}\varphi 0.1 \mathrm{~Hz}, \\
\text { grad }\end{array}$ & $\begin{array}{c}\varphi 0.01 \mathrm{~Hz} \\
\text { grad }\end{array}$ \\
\hline Control & $50,0 \pm 2,2$ & $45,5 \pm 1,3$ & $29,5 \pm 3,0$ & $15,9 \pm 3,6$ & $20,8 \pm 2,7$ & $33,0 \pm 4,4$ \\
\hline Group, & $\mathrm{Me}=51,0$ & $\mathrm{Me}=45,6$ & $\mathrm{Me}=30,3$ & $\mathrm{Me}=15,0$ & $\mathrm{Me}=21,0$ & $\mathrm{Me}=33,0$ \\
\hline $\mathrm{n}=17$ & $(46,5-52,9)$ & $(44,0-48,1)$ & $(23,4-33,6)$ & $(9,6-22,4)$ & $(16,0-27,8)$ & $(26,3-40,3)$ \\
\hline Patients before & $43,9 \pm 1,2^{*}$ & $40,0 \pm 2,3^{*}$ & $21,2 \pm 9,5^{*}$ & $12,2 \pm 5,0^{*}$ & $18,6 \pm 4,0$ & $27,0 \pm 5,3^{*}$ \\
\hline operations & $\mathrm{Me}=44,0$ & $\mathrm{Me}=39,5$ & $M e=26,7$ & $\mathrm{Me}=12,7$ & $\mathrm{Me}=19,3$ & $\mathrm{Me}=29,0$ \\
\hline $\mathrm{n}=40$ & $(38,0-45,2)$ & $(33,5-42,7)$ & $(9,7-34,3)$ & $(3,6-20,7)$ & $(11,4-26,8)$ & $(13,9-35,5)$ \\
\hline & $44,0 \pm 0,7$ & $41,4 \pm 0,8^{*}$ & $10,1 \pm 1,3^{*}$ & $7,4 \pm 1,1^{*}$ & $15,7 \pm 2,8^{*}$ & $18,2 \pm 2,6^{*}$ \\
\hline Patients during CB (5th minute), & $\mathrm{Me}=44,3$ & $\mathrm{Me}=41,7$ & $\mathrm{Me}=10,2$ & $\mathrm{Me}=7,0$ & $\mathrm{Me}=16,4$ & $\mathrm{Me}=18,3$ \\
\hline & $(43,2-44,6)$ & $(40,5-42,2)$ & $(8,7-11,9)$ & $(6,0-8,8)$ & $(12,4-19)$ & $(15,5-21,3)$ \\
\hline Patients in 1 day after & $44,3 \pm 0,6^{*} \diamond$ & $40,1 \pm 2,2^{*}$ & & $13,5 \pm 5,5^{*} \diamond$ & $17,2 \pm 3,2 * \diamond$ & $25,6 \pm 5,0 * \diamond$ \\
\hline operations & $\mathrm{Me}=44,4$ & $\mathrm{Me}=39,2$ & 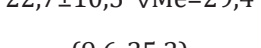 & $\mathrm{Me}=16,8$ & $\mathrm{Me}=18,2$ & $\mathrm{Me}=27,5$ \\
\hline $\mathrm{n}=40$ & $(43,2-45,6)$ & $(36,7-43,5)$ & & $(5,9-20,3)$ & $(11,1-23,3)$ & $(14,8-32,2)$ \\
\hline Patients in 7 days after & $44,5 \pm 1,3^{*} \diamond$ & $40,0 \pm 2,5^{*}$ & $22,6 \pm 10,4 * 0$ & $13,4 \pm 5,6 * \diamond$ & $17,6 \pm 3,7 * \diamond$ & $26,5 \pm 5,1^{*}$ \\
\hline operations & $\mathrm{Me}=44,5$ & $\mathrm{Me}=39,2$ & $\mathrm{Me}=23,8$ & $\mathrm{Me}=12,1$ & $\mathrm{Me}=17,5$ & $\mathrm{Me}=28,0$ \\
\hline $\mathrm{n}=40$ & $(41,3-49,9)$ & $(34,2-42,9)$ & $(11,0-37,2)$ & $(7,0-22,1)$ & $(11,4-26,1)$ & $(16,1-34,6)$ \\
\hline
\end{tabular}

Note:

1. * - Statistical significance of differences with respect to the control group at the level of $\mathrm{p}<0.05$.

2. $\diamond$-statistical significance of the differences with respect to the preoperative period $\mathrm{p}<0.05$.

Table 2: Comparison of biochemical parameters of blood serum of patients in relation to the control group, the preoperative period and the 1st day after surgery $(\mathrm{M} \pm \mathrm{Sd}$; $\mathrm{Me}$; (Min-Max)).

\begin{tabular}{|c|c|c|c|c|c|}
\hline \multirow{2}{*}{ Groups } & \multicolumn{5}{|c|}{ Parameters } \\
\hline & Glucose, mM & Total protein, $\mathrm{g} / \mathrm{l}$ & Albumin, $\mathrm{g} / \mathrm{l}$ & Urea,mM & Creatinine, mkM \\
\hline Control & $5,47 \pm 1,24$ & $74,1 \pm 4,7$ & $43,3 \pm 3,1$ & $5,0 \pm 1,54$ & $73,3 \pm 15,9$ \\
\hline Group, & $\mathrm{Me}=5,4$ & $\mathrm{Me}=73,4$ & $\mathrm{Me}=42,5$ & $\mathrm{Me}=4,9$ & $\mathrm{Me}=72$ \\
\hline $\mathrm{n}=17$ & $(4,1-5,7)$ & $(64,7-79,8)$ & $(38,3-47,2)$ & $(3,4-6,9)$ & $(56,2-93,4)$ \\
\hline Patients before & $7,1 \pm 2,3^{*}$ & $74,8 \pm 7,0$ & $40,8 \pm 7,0^{*}$ & $6,8 \pm 2,5^{*}$ & $106,8 \pm 24,4^{*}$ \\
\hline operations & $\mathrm{Me}=6,3$ & $\mathrm{Me}=76,2$ & $\mathrm{Me}=40,3$ & $\mathrm{Me}=6,4$ & $M e=103,6$ \\
\hline $\mathrm{n}=40$ & $(4,2-13,5)$ & $(58,6-85,7)$ & $(31,0-42,9)$ & $(2,0-13,2)$ & $(62,0-182,0)$ \\
\hline & $11,7 \pm 4,5^{*} \diamond \square$ & $41,5 \pm 7,8^{*}$ ○ & & & \\
\hline $\begin{array}{l}\text { Patients during } C B \\
\text { (5th minute), } n=16\end{array}$ & $\mathrm{Me}=11,4$ & $\mathrm{Me}=40,2$ & & & \\
\hline & $(5,6-30,0)$ & $(26,0-55,8)$ & & & \\
\hline Patients in 1 day after & $8,3 \pm 2 * \diamond$ & $58,6 \pm 6,4^{*} \diamond$ & $33,0 \pm 3,6^{*} \diamond$ & $8,3 \pm 2,3 * \diamond$ & $130,4 \pm 29,5^{*} \diamond$ \\
\hline operations & $\mathrm{Me}=8,0$ & $\mathrm{Me}=59,7$ & $\mathrm{Me}=33,7$ & $\mathrm{Me}=8,5$ & $\mathrm{Me}=119,4$ \\
\hline $\mathrm{n}=40$ & $(4,8-16)$ & $(37,3-70,0)$ & $(24,5-40,4)$ & $(4,6-14,9)$ & $(82,7-201,3)$ \\
\hline Patients in 7 days after & $7 \pm 2 * \square$ & $64,7 \pm 6,6^{*}$ ○ & $34,3 \pm 2,9 * \diamond$ & $9 \pm 3,0 * \diamond$ & $130,7 \pm 39,9^{*} \diamond$ \\
\hline operations & $\mathrm{Me}=6,5$ & $\mathrm{Me}=64,8$ & $\mathrm{Me}=34,7$ & $\mathrm{Me}=8,5$ & $\mathrm{Me}=122,3$ \\
\hline $\mathrm{n}=40$ & $(4,4-13,9)$ & $(51,3-74,2)$ & $(29,9-39,0)$ & $(4,5-14,4)$ & $(90,7-243,3)$ \\
\hline
\end{tabular}

Note:

1. * - Statistical significance of differences with respect to the control group at the level of $\mathrm{p}<0.05$.

2. $\nabla$-Statistical significance of the differences with respect to the preoperative period $\mathrm{p}<0.05$.

3. $\square$ - Statistical significance of differences with respect to the 1st day after operation $p<0.05$. 
Table 2 shows that in patients before surgery, an initially elevated levels of glucose, urea, and creatinine are determined versus the control group, that indicates the development of an initial inflammatory reaction and renal hypoperfusion as a result of Chronic Heart Failure (CHF). During treatment, a significant ( $p$ $<0.001$ ) increase in glucose, urea, and creatinine levels was noted as a result of a systemic inflammatory response $s$ an impact of $\mathrm{CB}$ and surgical trauma. The CB process leads to the development of renal hypoperfusion and the development of renal dysfunction in the early postoperative period (uremia), activation of stressactivating systems (hyperglycemia) and systemic inflammation (hypo albunemia) through endothelium damaged by the systemic inflammatory response. In addition, intra- and postoperative hemodilution associated with blood loss and its replenishment leads to hypoalbuminemia. By the 7 th day of the postoperative period, a positive dynamics of the studied biochemical parameters is noted. However, despite the positive trends, the level of the analyzed indicators did not significantly reach the preoperative "normal" values.

\section{Conclusion}

It was found that patients with coronary heart disease compared with healthy volunteers of the same age demonstrate decreasing in both dynamic and equilibrium surface tension by an average of 5-6 $\mathrm{mN} / \mathrm{m}$. This behavior of the changes indicates a significant increase in the concentration of surfactants in the blood serum of patients, which can be considered as an adaptive reaction of an organism in response to the development of CHD and CHF. It can be assumed that an increase in the surfactants concentrations leads to a decrease in friction at the phase boundary, in this case serum/endothelium, which reduces the energy loss due to friction between these phases and can positively affect the decrease in hydrodynamic resistance in the microcirculation system during the progression of coronary heart disease and CHF. The absence of the effect of the operation on subsequent changes in the tensiometric and rheological parameters of the serum of patients was established. Probably 7 days are not enough to change the composition of blood serum in relation to surfactants levels. The procedure for transferring patients to cardiopulmonary bypass does not cause changes in the dynamic and equilibrium surface tension of blood serum but leads to an increase in the sensitivity of the dilatation viscosity module to the oscillation frequency. Despite the absence of direct correlation between the biochemical and rheological parameters of the blood serum of patients, the study of surface tension allows reliable identification of patients with severe coronary heart disease and in the long term can become the basis for the development of a quick and cheap method of screening studies.

\section{Acknowledgment}

Authors are deeply grateful to Doctor of Chemistry V. B. Fainerman for his help in processing and interpreting the data, for advice and valuable comments when working on this article.

\section{References}

1. Chernyakhovskaya NE (2013) Correction of microcirculation in clinical practice. M Binom pp. 208.

2. SS Li, Liu Y, Li H, Wang LP (2019) Identification of psoriasis vulgaris biomarkers in human plasma by non-targeted metabolomics based on UPLC-Q-TOF/MS. European Review for Medical and Pharmacological Sciences 23(9): 3940-3950.

3. Kazakov VN, Fainerman VB, Kondratenko PG, Elin AF, Sinyachenko OV, et al. (2008) Dilational rheology of serum albumin and blood serum solutions as studied by oscillating drop tensiometry. Colloids Surfaces B 62: 77-82.

4. Kazakov VN, Knyazevich VM, Sinyachenko OV, Fainerman VB (2009) Interfacial Rheology of Biological Liquids: Application in Medical Diagnostics and Treatment Monitoring. Interfacial Rheology 1: 519-566.

5. Krishnan A, Wilson A, Sturgeon J, Siedlecki A (2005) Liquid-vapor interfacial tension of blood plasma, serum and purifiedprotein constituents thereof. Biomaterials 26: 3445-3453.

6. Kazakov VN, Sinyachenko OV, Fainerman VB, Pison U, Miller R (2000) Dynamic surface tensiometry in medicine. Amsterdam: Elsevier pp. 373.

7. Chevalier G, Stephen T, James L (2013) Earthing (Grounding) the Human Body Reduces Blood Viscosity-a Major Factor in Cardiovascular Disease. The journal of alternative and complementary medicine 19(2): 102-110.

8. Shishehbor MH, Venkatachalam S, Sun S, Clair DG, Sabik JF, et al. (2013) A Direct Comparisonof Early and Late Outcomes with Three Approaches to Carotid Revascularization and Open-Heart Surgery. J Am CollCardiol 62(21): 1948-1956

9. Dormandy JA (1974) Medical and engineering problems of blood viscosity. Biomed Eng 9(7): 284-291.

10. Kazakov VN, Fainerman VB, Kondratenko PG, Elin AF, Sinyachenko OV, et al. (2008) Dilational rheology of serum albumin and blood serum solutions as studied by oscillating drop tensiometry. Colloids Surfaces B 62(1): 77-82.

11. Morrow DA, de Lemos JA, Sabatine MS, Antman EM (2003) The search for a biomarker of cardiac ischemia. Clin Chem 49(4): 537-539.

12. Kazakov VN, Knyazevich VM, Sinyachenko OV, Fainerman VB, et al. (2009) Interfacial Rheology of Biological Liquids: Application in Medical Diagnostics and Treatment Monitoring. In "Interfacial Rheology". Progress in Colloid and Interface Science, Miller R, Liggieri L (Eds.), Brill Publ, Leiden 1: 519-566.

13. Kazakov VN, Barkalova EL, Levchenko LA, Klimenko TM, Fainerman VB, et al. (2011) Dilation rheology as medical diagnostics of human biological liquids. Colloids Surfaces 391: 190-194.

14. Fainerman VB, Trukhin DV, Igor I Zinkovychand, Miller R (2018) Interfacial tensiometry and rheometry of biological liquids in medicine. Adv Colloid Interface Sci 255: 34-46.

15.Zholob SA, Makievski AV, Miller R, Fainerman VB (2011) Advances in calculation methods for the determination of surface tensions in drop profile analysis tensiometry. In "Bubble and Drop Interfaces" / //, Progress in Colloid and Interface Science, Miller R, Liggieri L (Eds.), Brill Publ, Leiden 2: 39-60. 
16. Zholob SA, Makievski AV, Miller R, Fainermana VB (2007) Optimisation of calculation methods for determination of surface tensions by drop profile analysis tensiometry. Adv Colloid Interface Sci 134-135: 322329.

17. Lucassen J, Van den Tempel M (1972) Dynamic measurements of dilational properties of a liquid interface. Chem Eng Sci 27(6): 12831291.

ISSN: 2574-1241

DOI: $10.26717 /$ BJSTR.2020.26.004389

Khomutov EV. Biomed J Sci \& Tech Res

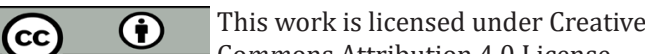
BY Commons Attribution 4.0 License

Submission Link: https://biomedres.us/submit-manuscript.php
18. Yu E Lyakh, Guryanov VG, Khomenko VN, Panchenko OA (2006) Basics of computer biostatistics: analysis of information in biology, medicine and pharmacy with the statistical package Med Stat pp. 214.

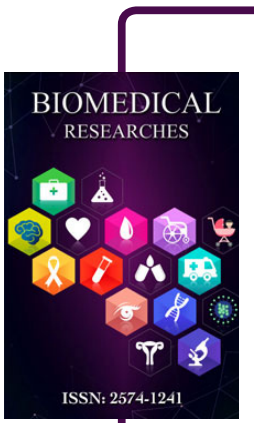

\section{Assets of Publishing with us}

- Global archiving of articles

- Immediate, unrestricted online access

- Rigorous Peer Review Process

- Authors Retain Copyrights

- Unique DOI for all articles

https://biomedres.us/ 